九州大学学術情報リポジトリ

Kyushu University Institutional Repository

\title{
Effect of Polypropylene Plastic Waste as Co- feeding for Production of Pyrolysis 0il from Palm Empty Fruit Bunches
}

\section{Kusrini, Eny}

Department of Chemical Engineering, Faculty of Engineering, Universitas Indonesia

Supramono, Dijan

Department of Chemical Engineering, Faculty of Engineering, Universitas Indonesia

Muhammad, Idrus Alhamid

Department of Mechanical Engineering, Faculty of Engineering, Universitas Indonesia

Pranata, Saeful

Department of Chemical Engineering, Faculty of Engineering, Universitas Indonesia

他

https://doi.org/10.5109/2328410

出版情報：Evergreen. 6（1），pp.92-97，2019-03. 九州大学グリーンアジア国際リーダー教育センター バージョン：

権利関係 : 


\title{
Effect of Polypropylene Plastic Waste as Co-feeding for Production of Pyrolysis Oil from Palm Empty Fruit Bunches
}

\author{
Eny Kusrini ${ }^{* 1}$, Dijan Supramono ${ }^{1}$, Muhammad Idrus Alhamid ${ }^{2}$, Saeful Pranata ${ }^{1}$, Lee \\ D. Wilson ${ }^{3}$, Anwar Usman ${ }^{4}$
}

\author{
${ }^{1}$ Department of Chemical Engineering, Faculty of Engineering, Universitas Indonesia, Kampus Baru-Depok \\ 16424, Indonesia \\ ${ }^{2}$ Department of Mechanical Engineering, Faculty of Engineering, Universitas Indonesia, Kampus Baru-Depok \\ 16424, Indonesia \\ ${ }^{3}$ Department of Chemistry, University of Saskatchewan, 110 Science Place, Saskatoon, Saskatchewan, Canada \\ S7N 5C9 \\ ${ }^{4}$ Department of Chemistry, Faculty of Science, Universiti Brunei Darussalam, Jalan Tungku Link, Gadong
} BE1410, Negara Brunei Darussalam

\begin{abstract}
*Corresponding author: Tel: (+62) 21—7863516 ext. 204; Fax: (+62)-21-7863515; E-mail: ekusrini@che.ui.ac.id
\end{abstract}

(Received December 28, 2018; accepted March 26, 2019)

\begin{abstract}
In this study, a pyrolysis oil product from slow co-pyrolysis of plastic waste (polypropylene, PP) with palm empty fruit bunches (EFB) was obtained using a fixed-bed reactor. The effect of EFB to PP mass ratio on the physical and chemical properties of pyrolysis oil product was studied. The effect of PP waste toward the properties for pyrolysis oil product yields a lesser amount of oxygenated species, where the $\mathrm{pH}$ is similar to a commercial fuel. Co-feeding of PP has a potential in improving the physical and chemical properties of the pyrolysis-oil product as a fuel by lowering its corrosiveness.
\end{abstract}

Keywords: slow co-pyrolysis, co-feeding, empty fruit bunches, polypropylene, pyrolysis oil

\section{Introduction}

Currently, the development of bioenergy as an alternative energy source is a key goal due to the decreasing availability of petrochemical fuels. One potential area of energy development is the utilization of biomass to produce bio-oil by the pyrolysis process. The pyrolysis method has economic advantages because it does not require pre-treatment of feedstock. Pyrolysis is one of the promising approaches to produce a renewable product and/or new chemicals ${ }^{1)}$. It is a method of short-chain decomposition through a high-temperature heating process without the use of oxygen that provides products such as biochar, biogasoline, and bio-oil ${ }^{1,2}$. The product yield of pyrolysis affected by some parameters such as temperature, gas residence tome, particle size, heating rate, and feedstock ${ }^{3)}$. By this method, reduced environmental pollution occurs and an increase in the value of waste to energy via conversion of agricultural biomass into bio-oil. Bio-oil production is very important because of the need to diminish environmental pollution and to offset the limited global availability of fossil fuels, and the potential to achieve valorization of waste into fuel products ${ }^{4)}$. Techno-economic analysis of bio-oil production process from palm empty fruit bunches (EFB) via fast pyrolysis using a fluidized-bed process has been reported ${ }^{4}$.

Palm EFB contains lignocellulose compounds, thus it represents a key resource for renewable energy production ${ }^{5)}$ ), especially for bio-oil products. EFB is an abundant waste biomass harvested in the tropic regions ${ }^{7)}$ that is increasingly more available due to the greater cultivation of palm. Although EFB can be used to produce a fertilized or burnt form to generate steam for electricity production ${ }^{8)}$, most of the EFB is disposed in landfills without proper treatment. Currently, EFB is used as compost or forage ${ }^{3)}$. Thus, a large amount of EFB can be used as a feedstock for bio-oil production ${ }^{9}$. Biomass contains carbon, hydrogen and oxygen at levels that differ from conventional fossil fuel resources ${ }^{6}$. This 
feedstock is often in solid form and has low energy density. Thus, the storage and transport is not as efficient according to the higher cost, when compared to hydrocarbon liquid fuels ${ }^{6}$. The quality of bio-oil is often determined by the nature of the biomass from which it is sourced ${ }^{10)}$.

EFB is a biomass source for bio-oil production but the bio-oil cannot be directly used as a fuel because has many undesirable properties such as low heating value, high acidity, high viscosity, high oxygen content, and high corrosiveness ${ }^{11)}{ }^{12}$. Thus, bio-oil from this process needs further innovation and improvement its quality for upgrading its properties related the suitability as fuel in the fuel infrastructure.

In order to reduce the oxygen compounds and increase the caloric value of pyrolysis oil from EFB, polypropylene (PP) plastic waste was added to the bio-oil production stream via slow co-pyrolysis. $\mathrm{PP}$ is the largest type of plastic waste in the world, one of the major components of municipal solid waste, and it contains about 14 wt.\% hydrogen atoms, thus it is appropriate as hydrogen source for co-pyrolysis process 13) 14). PP is classified as cheap hydrogen donor atoms because the hydrogen/carbon ratio is about $1-2^{15}$ ). $\mathrm{PP}$ is also simply changed into liquid and gas hydrocarbons by pyrolysis process ${ }^{11}$. As we know that the pyrolysis of PP can be done by the presence of a catalyst or absence of a catalyst. These process is composed by four steps, namely initiation, transfer, decomposition and termination ${ }^{16)}$. A key goal of this study was to utilize EFB to produce pyrolysis oil with the addition of PP plastic waste as the initiator for the reaction. This type of plastic was selected because previous research indicated that such materials produce quality products in the form of pyrolysis oil. The utilization of biomass for bio-oil production has been achieved using the fast pyrolysis method without any additive mixing, but the produced bio-oil tends to have elevated oxygen levels ${ }^{17}$. Co-pyrolysis is a process of combining two types of raw materials into the pyrolysis process, where numerous studies indicate that such co-pyrolysis can improve the quality and quantity of bio-oil products ${ }^{11)}{ }^{15}$.

In particular, the addition of plastics in biomass pyrolysis increase yield and the bio-oil caloric value, as compared to pyrolysis of biomass alone. The effect is caused by the presence of paraffin-containing hydrocarbon polymers, isoparaffin, olefin, naphtha and aromatic systems ${ }^{18)}$.

In this study, we produced pyrolysis oil from EFB mixed with PP waste using slow co-pyrolysis at $500^{\circ} \mathrm{C}$ with a fixed bed reactor.

\section{Experimental}

\section{The Materials}

Raw materials in the form of PP plastic waste and EFB. $\mathrm{PP}$ waste was obtained from the waste contained in the greater Jakarta area. All PP and EFB are oven dried at $80^{\circ} \mathrm{C}$, to yield materials with moisture content below
$10 \%$. After that, raw materials were chopped with an auxiliary grinder machine up to a size of $\pm 3-5 \mathrm{~cm}$.

\section{Preparation of pyrolysis oil product}

The reactor design for the slow co-pyrolysis method and preparation of pyrolysis oil product was adapted from the reports by Supramono et al. ${ }^{19)}$ and Kusrini et al. ${ }^{20}$. Slow co-pyrolysis was done in a stainless steel reactor in the cylindrical type with a length of $25 \mathrm{~cm}$ and a diameter of $6 \mathrm{~cm}$. A feedstock composed of EFB and PP were put in a boat made of a half cylinder size with a length of $11 \mathrm{~cm}$ and diameter of $5 \mathrm{~cm} .20 \mathrm{~g}$ feeds from EFB and PP wastes were used for each experiment. The mass ratio of feedstock PP waste to EFB was varied to be 0:100, 25:75, 50:50, 75:25 and 100:0. The boat was located horizontally inside in the cylindrical reactor. Nitrogen flow is adjusted to be $3 \mathrm{~L} / \mathrm{h}$ in an up-flow reactor configuration to fulfil the maximum residence time of $7-$ 10 seconds to avoid by-products and/or secondary reaction of plastic. Prior to pyrolysis, the reactor was flushed with nitrogen gas for 15 min with a flow rate of $750 \mathrm{~mL} / \mathrm{min}$. The heating rate of the pyrolysis process was maintained and set at $5{ }^{\circ} \mathrm{C} / \mathrm{min}$ to heat nitrogen gas at $500{ }^{\circ} \mathrm{C}$. After reaching $500{ }^{\circ} \mathrm{C}$, the temperature was maintained for $30 \mathrm{~min}$ for each run to produce greater yield of pyrolysis oil product. Then, the vapours were delivered to the condenser by cooling water at $10^{\circ} \mathrm{C}$ to allow condensation of the pyrolysis oil. The pyrolysis oil was collected in a bottle for quantitative and qualitative analysis of the identified compounds. Schematic representation of the production of pyrolysis oil is shown in Fig. 1.

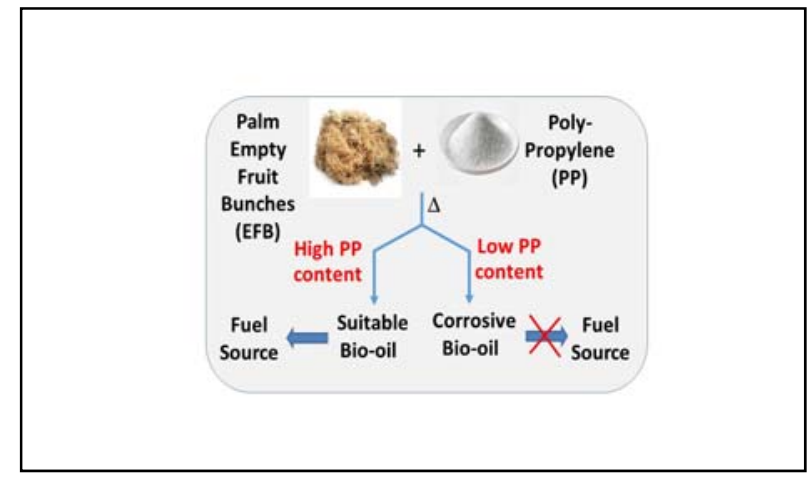

Figure 1. Schematic process for production of pyrolysis oil from EFB and PP plastic waste

\section{Characterization}

Volatile matter was measured in accordance with ASTM standard no. 3175, where the size of EFB is near 1-3 cm and a weight of $2 \mathrm{~g}$. The sample was placed in a porcelain crucible and kept in a furnace at $550{ }^{\circ} \mathrm{C}$ for 10 min and weighted after cooling at room temperature, then stored at desiccator. The composition of pyrolysis oil product was analyzed by gas chromatography-mass spectrometry (NIST GCMS-QP1010 Ultra Shimadzu, 
UK). The pyrolysis-oil was extracted using diethyl ether solvent and concentrated with nitrogen gas. Thermal analysis of EFB and PP wastes were determined by thermogravimetric analysis (Perkin Elmer STA 6000). The viscosity of pyrolysis oil was determined using a Saybolt universal viscometer at $40^{\circ} \mathrm{C}$. The results were compared against with those of commercial fuels.

\section{Results and Discussion}

\section{Characterization}

The proximate analysis was conducted to determine the water content, ash, solid carbon, heating value, and volatile matter in the feed. The ultimate test was performed to determine the contents of $\mathrm{C}, \mathrm{N}, \mathrm{O}$, and $\mathrm{S}$, where the results of the proximate and ultimate analysis of EFB are shown in Table 1.

Table 1. Proximate and ultimate analysis of EFB and PP

\begin{tabular}{|c|c|c|}
\hline Parameter & EFB & PP \\
\hline & \multicolumn{2}{|c|}{ Proximate Test (wt.\%) } \\
\hline Water content & 13.64 & 10.00 \\
\hline Ash content & 4.88 & 0.09 \\
\hline Volatile matter & 65.86 & 89.70 \\
\hline Fixed carbon & 15.56 & 0.21 \\
\hline & \multicolumn{2}{|c|}{ Ultimate Test (wt.\%) } \\
\hline Carbon & 45.94 & 83.10 \\
\hline Hydrogen & 5.64 & 11.77 \\
\hline Nitrogen & 3.99 & 0.14 \\
\hline Sulfur & 0.14 & 0.16 \\
\hline Oxygen & 24.84 & 4.83 \\
\hline
\end{tabular}

The water content in EFB and PP are 13.64 and 10\%, respectively. The presence of water can reduce the heat value, especially the low heating value and combustion temperature. Water can increase the ignition delay or burning delay, and also lower the combustion rate when compared to commercial fuel ${ }^{21)}$. Water can also reduce the viscosity of pyrolysis oil product, thus making it more feasible to be used as a fuel. The oxygen content for EFB is high enough to reach $24.84 \%$, and contributes to higher levels of oxygenated species in pyrolysis oil with lower caloric value.

The volatile matter is the amount of substance that evaporates during the combustion process. The higher volatile matter in biomass can result in higher bio-oil yields ${ }^{22)}$. The volatile matter of EFB and PP are 65.86 and $89.70 \%$, respectively. PP has very low ash content $(0.02 \%)$, thus it has utility as a precursor in pyrolysis oil production. High levels of ash content can cause pyrolysis oil to be more corrosive and lower its durability. Diebold ${ }^{23)}$ reported that the compounds produced from high ash levels often contain alkali ( $\mathrm{Na}, \mathrm{K}),(\mathrm{Mg}, \mathrm{Ca})$, and other species such as $\mathrm{S}, \mathrm{Cl}, \mathrm{N}, \mathrm{P}, \mathrm{Si}, \mathrm{Al}$, along with heavy metals such as $\mathrm{Cd}, \mathrm{Zn}, \mathrm{As}, \mathrm{Pb}, \mathrm{Cu}$, and $\mathrm{Hg}$.

\section{Thermal analysis}

Thermal behavior of EFB, PP and EFB-PP were evaluated using thermogravimetric analysis (TGA). The thermal degradation of EFB and PP bound with the complex chemical reaction and their composition. This data can be used to investigate its thermal properties and the reaction kinetics. It can be accomplished from TGA curve that show the mass loss at increasing temperature and a fixed heating rate ${ }^{24)}$. The high temperature thermal decomposition of the EFB, PP and EFB with ratio 50:50 (wt.\%) are presented in Figures 2(a) and (b).

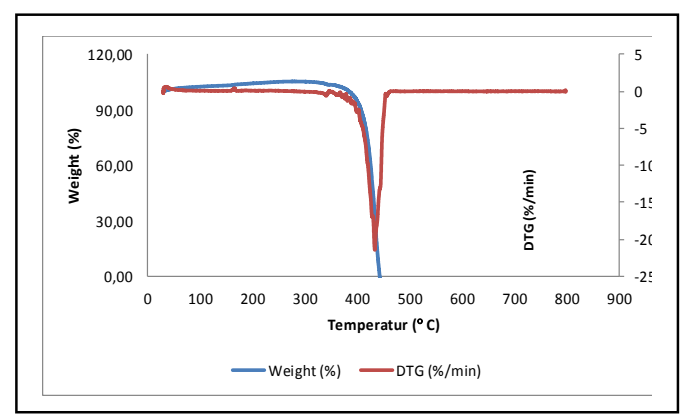

(a)

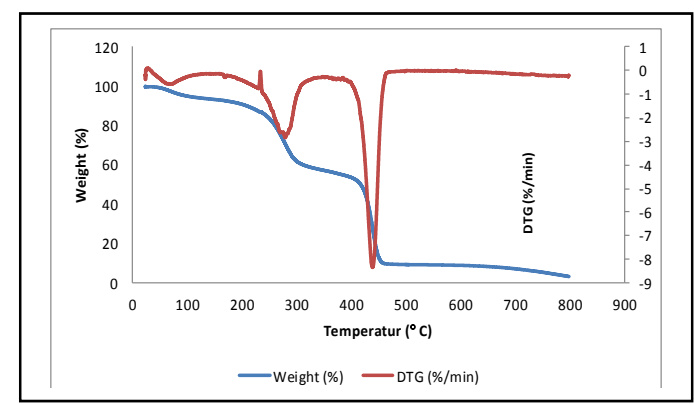

(b)

Figure 2. TG and DTG curves of (a) PP and (b) EFB and

PP waste with mass ratio of 50:50

The first stage of EFB decomposed is from room temperature to $200^{\circ} \mathrm{C}$. The main thermal decomposition stage of EFB starts near $200^{\circ} \mathrm{C}$ to $490^{\circ} \mathrm{C}{ }^{20)}$. This TGA profiles is also similar with reported for EFB by Lee et al. 24) with peak decomposition at 66, 295 and $356^{\circ} \mathrm{C}$. The final decomposition stage occurs between 490 to $730^{\circ} \mathrm{C}$. For EFB, it can be seen that an event at higher temperature up to $782^{\circ} \mathrm{C}$. It can be inferred that carbonaceous residues are present at approximately $28 \%$ of the total sample as a residue that remain in the crucibles, in agreement with TGA profiles reported for coal waste by Mohamed et al. ${ }^{25}$ ). On the other hand, the main thermal decomposition of PP occurs between $373^{\circ} \mathrm{C}$ to $452^{\circ} \mathrm{C}$ (see Fig. 2(a)) in line with the trend observed for Miscanthus biomass ${ }^{26)}$.

The experimental analysis of thermal degradation of EFB:PP with a weight ratio of $50 \mathrm{wt}$ \% occurs firstly at 
$23-83^{\circ} \mathrm{C}$, with a second event at $200-315^{\circ} \mathrm{C}$, and a third event at $375-490^{\circ} \mathrm{C}$ (see Fig. 2(b)). This thermogram is combined from both EFB and PP. The strong peak at $375-490^{\circ} \mathrm{C}$ is indicated by the decomposition of PP.

\section{Effect of co-feeding PP towards Yield of Pyrolysis-oil}

The effect of the addition of PP wastes on the yield of the solid, liquid and gas fraction products depicted in Fig. 3. PP has a low methyl fraction that affects each carbon atom of its main chains, causing PP to have a smaller tensile strength. The total mass of solid and liquid fractions was analyzed to examine the effects of co-feeding of EFB and PP. The results showed that increasing the total mass of PP and EFB up to $100 \mathrm{wt} . \%$ resulted in pyrolysis oil products of 17.4 and 5.05 wt.\%, respectively. The increasing PP waste to EFB weight ratios of 10:90, 25:75, 50:50 and 75:25 wt.\% produce a variable yield of pyrolysis oil products at 9.0, 7.8, 6.8 and 6.3 wt.\%, respectively (see Fig. 4). In this study, when PP increase the yield of pyrolysis oil decrease because of the PP degradation involved the four steps reactions, namely initiation, transfer, decomposition and termination ${ }^{16)}$, however, their reaction of PP is not total and perfect occurred thus it effected the pyrolysis oil product.

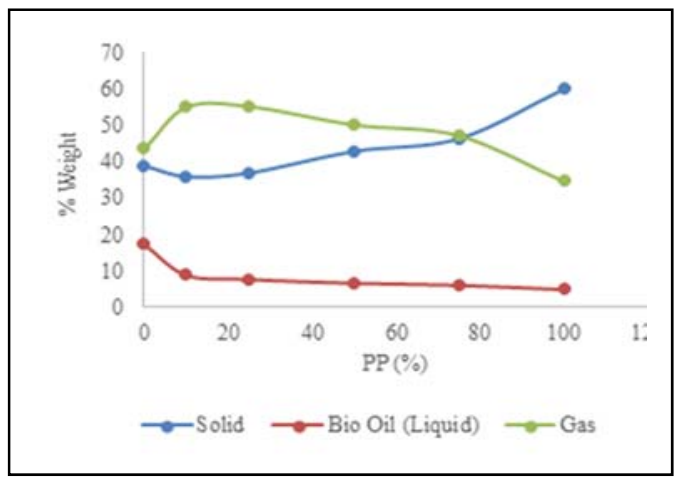

Figure 3. Comparison of solid, liquid and gas fractions with different weight ratios of EFB and PP

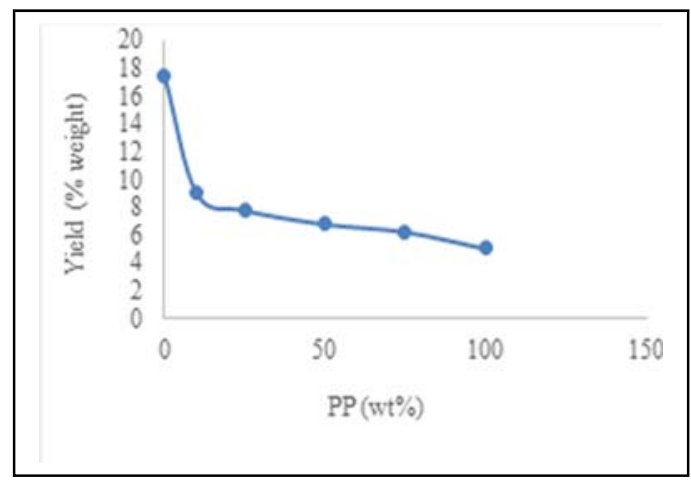

Figure 4. Comparison of \% yield of pyrolysis oil product with different weight ratios of PP plastic waste

\section{Component Analysis of Pyrolysis oil Product}

GC-MS was used to analyze the chemical components of the pyrolysis oil product after the pyrolysis oil was extracted using a diethyl ether solvent was along with concentration by nitrogen gas. The chemical compounds contained in the pyrolysis oil product are identified based on the relative peak area values (\%) in the GC-MS chromatogram. Based on the obtained results, it can be concluded that various compounds are present in the pyrolysis oil product. The aromatic and aliphatic compounds called non-oxygenated compounds, and furans, ketones, aldehydes, acids, phenols, and ketones, referred to as oxygenated compounds were identified in the pyrolysis-oil (see Fig. 5). The results showed that an increase of the total mass of PP and EFB up to $100 \mathrm{wt} . \%$, yielded pyrolysis oil products at 17.4 and 5.05 wt.\%, respectively. Further, an increase of the PP plastic waste to EFB ratios of $10: 90,25: 75,50: 50$ and $75: 25$ wt.\% produced pyrolysis oil products of 9.0, 7.8, 6.8 and 6.3 wt.\%, respectively. The pyrolysis oil product is composed of aromatic, aliphatic, phenol, furan, alcohol, aldehyde, ketone and acid compounds. In addition to these compounds, there are also complex hydrogenated compounds.

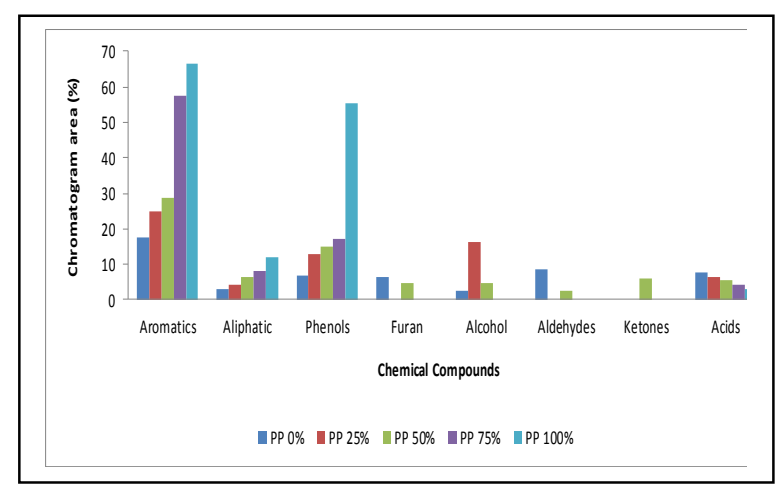

Figure 5. The composition of pyrolysis oil product that produced from the PP:EFB with weight ratio of $0: 100$

\section{Viscosity Test and pH of Pyrolysis oil Product}

The viscosity and $\mathrm{pH}$ test of the pyrolysis oil was measured to test whether pyrolysis oil can be further utilized as a commercial fuel source. As a fuel, pyrolysis oil should not have a low $\mathrm{pH}$, because it can cause pyrolysis oil to be corrosive. Viscosity analysis is required as a physical property of the fluid that represents the rapid or slow fluid flowability. If the fuel has a viscosity that is too high, it will be hard to flow causing mechanical damage.

In this study, the pyrolysis oil product with variable PP weight ratios of 0: 100, 50:50, and 100: 0 (wt.\%) were investigated. For samples with variable PP and EFB, it is seen that the viscosity of diesel is very close to the pyrolysis-oil product in the absence of EFB. The properties of pyrolysis oil are further listed in Table 2 The viscosity of pyrolysis oil products are higher (4.2 to 
7) than that found for the commercial fuels (4). The presence of very high lignin compounds in EFB causes the pyrolysis oil to become more viscous, and the pyrolysis oil product becomes unstable ${ }^{27)}$.

Tabel 2. Comparison properties of pyrolysis oil product vs commercial fuel

\begin{tabular}{cccccc}
\hline \multirow{2}{*}{ Properties } & $\begin{array}{c}\text { EFB (100 } \\
\text { wt.\%) }\end{array}$ & $\begin{array}{c}\text { EFB:PP } \\
\text { ratio of } \\
50: 50 \\
\text { wt.\% }\end{array}$ & $\begin{array}{c}\text { PP } \\
(100 \\
\text { wt. } \\
\%)\end{array}$ & $\begin{array}{c}\text { Dies } \\
\text { fel }\end{array}$ & $\begin{array}{c}\text { Gas } \\
\text { fuel }\end{array}$ \\
\hline viscosity (cSt) & 7 & 4.8 & 4.2 & 4 & 1.17 \\
pH & 3 & 3 & 5 & 5 & 5 \\
\hline
\end{tabular}

The $\mathrm{pH}$ of pyrolysis oil product without PP and $50 \mathrm{wt} . \%$ of $\mathrm{PP}$ have a similar $\mathrm{pH}$ value of 3 . However, for pyrolysis-oil products with the weight ratio of PP is 100 wt.\%, the $\mathrm{pH}$ increased and reached to $\mathrm{pH}$ 5. The $\mathrm{pH}$ of pyrolysis oil product with EFB at 100 wt.\% is $\mathrm{pH} 3$ and indicates that the pyrolysis oil is more acidic than the bio-oil product with PP at 100 wt.\%. Thus, pyrolysis oil product from pure of EFB contained more oxygenated compounds that favour facile oxidization over carbonaceous materials such as industrial coal waste ${ }^{21)}$. Oxidation reactions that occur not only change the color of pyrolysis oil product to a black colour but it also produced acidic radical compounds. Therefore, the pyrolysis-oil product using EFB of 100 wt.\% is acidic. With its high acid content, the pyrolysis-oil product from 100 wt.\% biomass cannot be used as a fuel source due to considerations of corrosiveness ${ }^{11)}{ }^{12)}$.

The effects are caused by the role of PP plastics in reducing the content of oxygenated species in the pyrolysis oil product, where it can inhibit the occurrence of oxidation reactions which result in pyrolysis oil with greater acidity. The higher the proportion of PP waste in the precursor led to the yield of a pyrolysis oil product with lesser oxygenated compounds. Increasing the weight ratio of PP waste can produce pyrolysis oil product with less oxygenated products.

The $\mathrm{pH}$ of pyrolysis oil produced by PP waste (100 wt.\%) is $\mathrm{pH}$ 5, which is a weakly acidic in nature. This is due to the lack of oxygen content in PP waste and the greater hydrogen content, so it has a lesser tendency to oxidize. Therefore, the color of pyrolysis oil product with PP (100 wt.\%) is more stable than the product derived from EFB at 100 wt.\%.

Comparison of the color of pyrolysis oil products for PP (100 wt.\%), EFB (100 wt.\%) and EFB:PP ratio (50:50 wt.\%) is shown in Fig. 6. All color is yellowish and clear. For pyrolysis oil product with PP (100 wt.\%) is yellow more thick. Both EFB (100 wt.\%) and EFB:PP ratio (0:50 wt.\%) are not significant different from each other.

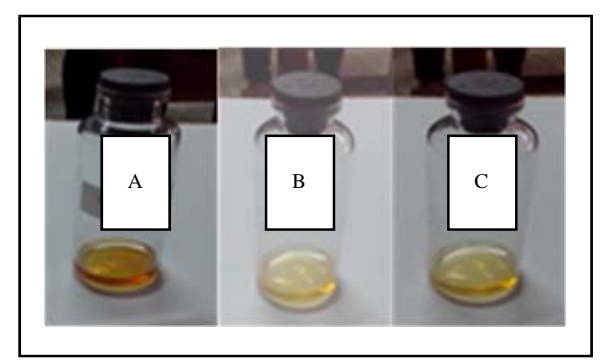

Figure 6. Color of pyrolysis oil products for A. PP waste (100 wt.\%), B. EFB (100 wt.\%), and C. with EFB:PP weight ratios of 50:50 wt.\%

\section{Conclusion}

We have investigated the pyrolysis oil properties that resulted from mixtures of EFB and PP by using slow co-pyrolysis. The physical and thermal properties of EFB and PP were characterized using a proximate ultimate test and TGA. In the case of EFB, it can be seen that a thermal event at high temperatures (up to $782^{\circ} \mathrm{C}$ ) that yields residues of approximately $28 \%$ of the sample weight that remain in the crucibles. The characteristics of the pyrolysis oil was analyzed by GC-MS. The slow co-pyrolysis process was conducted at a heating rate of $5^{\circ} \mathrm{C} / \mathrm{min}$ at $500^{\circ} \mathrm{C}$ in the presence of $750 \mathrm{~mL} / \mathrm{min} \mathrm{N}_{2}$ gas, with total weight of EFB:PP of $20 \mathrm{~g}$ for 30 minutes. The total mass of solid fraction and liquid fraction were analyzed to assess the effects of co-feeding of PP. The effect of PP waste towards the properties for pyrolysis-oil product has lower levels of oxygenated compounds, where the $\mathrm{pH}$ is similar with that of commercial fuels. Pyrolysis oil products with PP waste of $100 \mathrm{wt} . \%$ was demonstrated to be less acidic due to the presence of aromatic and aliphatic compounds. PP lowers the corrosivity of pyrolysis oil so that it can be utilized further as a suitable fuel source.

\section{Acknowledgment}

The authors greatly acknowledge the Universitas Indonesia.

This article's publication is partially supported by the United States Agency for International Development (USAID) through the Sustainable Higher Education Research Alliance (SHERA) Program for Universitas Indonesia's Scientific Modeling, Application, Research and Training for City-centered Innovation and Technology Project, Grant No. AID-497-A-1600004, Sub Grant No. IIE-00000078-UI-1.

\section{References}

1) A.A. Salema, R.M. W.Ting, and Y. K. Shang, Bioresource Technology 274, 439-446 (2019). 
2) A.S. Chaurasia, and B.D. Kulkarni, Energy Education Science \& Technology, 16, 31-43 (2005).

3) X. Lim, A. Sanna, and J. M. Andrésen, Fuel 119 (2014) 259-265 (2014).

4) T. X. Do, Young-il Lim, and H.Yeo, Energy Conversion and Management 80, 525-534 (2014).

5) T. X. Do, and Young-il Lim, Renewable Energy 90, 307-318 (2016)

6) G. Perkins, T. Bhaskar, and M. Konarova, Renewable and Sustainable Energy Reviews 90, 292-315 (2018).

7) G. K. Parshetti, A. Quek, R. Betha, and R. Balasubramanian, Fuel Processing Technology 118, 228-234 (2014).

8) Y. Furutani, K. Norinaga, S. Kudo, J.-I. Hayashi, T. Watanabe, EVERGREEN Joint Journal of Novel Carbon Resource Sciences \& Green Asia Strategy, 04 (04), 24-29 (2017).

9) S.H. Chang, Biomass Bioenergy 62, 174-181(2014).

10) D.D. Das, M. I. Schnitzer, C. M. Monreal, and P. Mayer, Bioresource Technology, 100, 6524-6532 (2009).

11) H. Shafaghata, H. W. Lee, Y.F. Tsang, D. Oh, J. Jae, S.-C. Jung, C. H. Ko, S. S. Lam, and Y.-K. Park, Chemical Engineering Journal 366, 330-338 (2019).

12) Y. Zhao, Y. Wang, D. Duan, R. Ruan, L. Fan, Y. Zhou, L. Dai, J. Lv, and Y. Liu, Bioresource Technology, 249, 69-75 (2018).

13) B. Zhang, Z. Zhong, K. Ding, and Z. Song, Fuel, 139, 622-628 (2015).

14) R. Miandad, M.A. Barakat, M. Rehan, A.S. Aburiazaiza, I.M.I. Ismail, and A.S. Nizami, Waste Management, 69, 66-78 (2017).

15) D. Duan, Y. Wang, L. Dai, R. Ruan, Y. Zhao, L. Fan, M. Tayier, Y. Liu, Bioresource Technology, 241 207213 (2017).

16) R. Miandad, M.A. Barakat, Asad S. Aburiazaiza, M. Rehan, I.M.I. Ismail, and A.S. Nizami, International Biodeterioration \& Biodegradation, 119, 239-252 (2017)

17) R. Bayerbach, V.D. Nguyen, U. Schurr and D. Meier, J. Anal. Appl. Pyrolysis 77(2), 95-101 (2006).

18) F. Abnisa, W.M.A. Wan Daud and J.N. Sahu, Environ Prog Sust Energy, 33,1026-33 (2014).

19) D. Supramono, E. Kusrini, H. Yuana, Journal of the Japan Institute of Energy, 95, 621-628 (2016).

20) E. Kusrini, S. Pranata, D. Supramono, V. Degirmenci, A. A. Bawono, F.N. Ani, International Journal of Technology, 9(7), 1498-1508 (2018).
21) D.C. Elliott, Relation of Reaction Time and Temperature to Chemical Composition of Pyrolysis Oils. Pyrolysis Oils from Biomass, E.J. Soltes and T.A. Milne, eds., ACS Symposium Series 376, 55-65 (1994).

22) W. Jung, K. Singh and Zondlo, J. Agriculture, 3, 12-32 (2008).

23) J. Diebold, A Review of the Chemical and Physical Mechanisms of the Storage Stability of Fast Pyrolysis Bio-oils. Lakewood, Colorado: Thermalchemie, Inc. (2000)

24) X. J. Lee, L. Y. Lee, S. Gan, S. Thangalazhy-Gopakumar, and H. K. Ng, Bioresource Technology, 236 155-163 (2017).

25) M. H. Mohamed, M. Pirlot, M. K. Danquah, and L. D. Wilson, Journal of Materials Science and Chemical Engineering, 5, 12-24 (2017).

26) L. Dehabadi, M. H. Mahaninia, M. Soleimani, and L. D. Wilson, ACS Sustainable Chemistry \& Engineering, 5(4), 2970-2980 (2017).

27) R. Bayerbach and D. Meier, J. Anal. Appl. Pyrolysis 85(1), 98-107 (2009). 